\title{
Does Statin or ASA Affect Survival When Prostate Cancer Is Treated with External Beam Radiation Therapy?
}

\author{
J. Caon, ${ }^{1}$ M. Paquette, ${ }^{2}$ J. Hamm, ${ }^{3}$ and T. Pickles ${ }^{1,2}$ \\ ${ }^{1}$ BC Cancer Agency Radiation Therapy Program, BC Cancer Agency, Vancouver Centre, 600 West 10th Avenue, \\ Vancouver, BC, Canada V5Z 4E6 \\ ${ }^{2}$ University of British Columbia, 2329 West Mall, Vancouver, BC, Canada V6T $1 Z 4$ \\ ${ }^{3}$ Cancer Surveillance \& Outcomes, Population Oncology, BC Cancer Agency, 600 West 10th Avenue, \\ Vancouver, BC, Canada V5Z 4E6 \\ Correspondence should be addressed to J. Caon; jcaon-02@bccancer.bc.ca
}

Received 2 November 2013; Revised 13 January 2014; Accepted 25 January 2014; Published 3 March 2014

Academic Editor: Katsuto Shinohara

Copyright (C) 2014 J. Caon et al. This is an open access article distributed under the Creative Commons Attribution License, which permits unrestricted use, distribution, and reproduction in any medium, provided the original work is properly cited.

\begin{abstract}
Background. Prior studies evaluating the effect of statins or acetylsalicylic acid (ASA) on the survival of men receiving prostate cancer were treatment have reported conflicting results, and have not adjusted for comorbidity. Our aim is to investigate the influence of statins and ASA on prostate cancer survival, when comorbidity is adjusted for, in men treated with external beam radiation therapy (EBRT) for prostate cancer. Methods. A cohort of 3851 patients with prostate cancer treated with curative EBRT \pm androgen deprivation therapy (ADT) between 2000 and 2007. Stage, treatment, medication use, and Charlson comorbidity index (CCI) scores were analyzed. Results. Median followup was 8.4 years. Mean age was 70.3 years. Neoadjuvant ADT was used in $67 \%$. Statins were used in $23 \%$, ASA in $24 \%$, and both in $11 \%$. Comorbidity scores were 0 in $65 \%, 1$ in $25 \%$, and $\geq 2$ in $10 \%$ of patients. Statin and ASA use were associated with increased age and comorbidity. Although statin and ASA use were significantly associated with improved prostate cancer specific survival (PCSS) on univariate analysis, neither were on multivariate analysis. Conclusion. Neither statin nor ASA use impacted PCSS on multivariate competing risks analysis. Survival was impacted by increased comorbidity as well as statin and ASA use.
\end{abstract}

\section{Introduction}

As a medication class, 3-hydroxy-3-methyl-glutaryl-CoA reductase inhibitors, commonly known as statins, are prescribed to lower cholesterol and reduce the risk of death from cardiovascular disease [1]. However, statins may also modulate prostate cancer through alteration in the cholesterol levels required for signal transduction of prostate cancer cells $[2,3]$. Statins may reduce androgen receptor expression and activity which could lead to reduced prostate cancer cell proliferation and increased apoptosis $[4,5]$ and a reduction in prostate specific antigen (PSA) release by such cells [4]. A number of other characteristics important to a neoplastic cell may also be altered in the presence of statin medications [6].

Acetylsalicylic acid (ASA) is an antiplatelet agent [7]. The effect on cancer is felt to be related to its properties as a nonsteroidal anti-inflammatory, particularly its effect on COX-2 receptors [8]. There is also a complex interplay between blood coagulation and cancer [9].

Studies evaluating the effect of statins or ASA on outcomes of men receiving curative intent treatment for prostate cancer have reported conflicting results. Acetylsalicylic acid has been associated with a decreased risk of prostate cancer [10]. In men with a preexisting diagnosis of prostate cancer, a prospective study did not show an association between this medication and prostate cancer death [11]; this is in contrast to a more recent study which found a lower risk of prostate cancer death in users of acetylsalicylic acid [12]. Some reports have suggested that statin use was associated with improved biochemical control $[13,14]$ but its effect in survival is less clear $[13,15,16]$.

While differences in the health of users and nonusers of certain medications, such as statins, may impact survival outcomes [17], data accounting for comorbidity among patients 
with prostate cancer remains lacking. In 2010, an editorial by D'Amico [17] advocated for the inclusion of comorbidity in studies assessing the impact of such medications. This study investigates associations between prostate cancer survival and statin and/or ASA use in men treated with curative intent radiation therapy, after adjusting for comorbidity.

\section{Methods and Materials}

A retrospective electronic chart review was conducted of patients with newly diagnosed localized prostate cancer treated in British Columbia (BC) with curative intent external beam radiation therapy (EBRT) for prostate cancer from January 1, 2000, to December 31, 2007. The BC Cancer Agency (BCCA) is a provincial cancer care institution that managed five regional centres providing all of the radiation therapy in $\mathrm{BC}$ during the study era. The study period was chosen because statin use was relatively uncommon before this time. Data were obtained from electronic linkage to existing data sources, including tumor marker, cancer registry, and death registry records, supplemented by review of the electronic chart for comorbidity and medication use.

Of initial 6144 patients, 2091 were excluded because they were not treated with EBRT. 4053 charts were reviewed and additional 202 patients were excluded because they had nonadenocarcinoma histology, noncurative treatment intent, prior orchiectomy, postprostatectomy radiation, brachytherapy boost, incomplete radiation course, incomplete electronic records, or no information about medication use. The final cohort included 3851 subjects.

Patient characteristics analyzed were age at diagnosis, income level (generated from tables of average income by postal code), and comorbidity using the Charlson comorbidity index (CCI) which was collected retrospectively by review of charts. The CCI is the most widely used tool to measure comorbidity and is valid in predicting mortality risk in a number of conditions, including cancer [18]. Specific comorbid conditions, including myocardial infarction, congestive heart failure, peripheral vascular disease, cerebrovascular disease, dementia, chronic obstructive pulmonary disease, connective tissue disease, peptic ulcer disease, liver disease (mild to severe), diabetes (with or without end organ damage), hemiplegia, renal disease (moderate to severe), malignancy, leukemia, lymphoma, metastatic solid malignancy, and AIDS, are weighted with different scores [19]. As prostate cancer was present in all subjects, this was not included in the Charlson score generated.

Statin and ASA medication use was coded from documentation at the time of initial consultation, which included referring physician notes, consultation reports as well as the patients written list of medication provided at the time of treatment consultation. "Statins" included a range of different types: atorvastatin, rosuvastatin, pravastatin, simvastatin, lovastatin, pitavastatin, fluvastatin, and statin not otherwise specified (NOS). "ASA" included acetylsalicylic acid only. Duration of medication use was not analyzed.

Clinicopathologic characteristics analyzed were stage, Gleason score, and initial prostate specific antigen (iPSA), allowing classification into a National Comprehensive Cancer Network (NCCN) risk group (low, intermediate, and high risk). Treatment characteristics included EBRT dose, adjuvant androgen deprivation therapy (ADT) use, and ADT duration. The year of radiation treatment was stratified at the median (2004).

Prostate cancer specific survival (PCSS) and overall survival (OS) were the primary endpoints of this analysis. Biochemical control and metastasis-free endpoints were not feasible due to nonstandardized followup practices and nonuniform indications for imaging or intervention upon relapse.

Descriptive statistics with cross-tabulations were employed. Analysis of survival endpoints was completed using univariate Kaplan-Meier statistics; univariate and multivariate hazard ratio models using Fine and Gray's competing risks analysis [20]. Data analyses were completed using Statistical Package for Social Sciences version 17.0 (SPSS, Chicago, IL, USA) and the SAS statistical software package (SAS version 9.3; SAS Institute Inc., Cary, NC). Significance was defined as $P \leq 0.05$. The study was approved by the Research Ethics Board of the University of British Columbia.

\section{Results}

Clinicopathologic characteristics of the entire cohort and according to prostate cancer risk groups are summarized in Table 1 . The mean age was 70.3 years (range 45 to 88 years). The mean EBRT dose was $70.9 \mathrm{~Gy}$. Most patients (67\%) received neoadjuvant $\mathrm{ADT}$ (mean duration 11.9 months). The distribution of prostate cancer risk groups was high risk in $44 \%$, intermediate risk in $40 \%$, and low risk in $14 \%$. Charlson comorbidity scores were 0 in $65 \%, 1$ in $25 \%$, and $\geq 2$ in $10 \%$ of subjects. Comorbidity indices were not associated with prostate cancer risk group $(P=0.425)$ or age $(P=0.120)$.

As expected there were significant differences $(P<$ 0.001 ) between statin and ASA users and nonusers in regard to Charlson comorbidity scores (Table 1), with increasing comorbidity being associated with increased use of these medications. Overall, statins were used in 914 (24\%) patients. Statin users were older $(P=0.013)$ and had a higher CCI score $(P<0.001)$ and a lower income level $(P=0.04)$. ASA medications were used in 917 (24\%) patients. These patients were also older $(P<0.001)$ with higher CCI scores $(P<$ $0.001)$.

Median followup for survival was 8.4 years. The association between statin or ASA use with PCSS and OS at 10 years is shown in Table 2. On Fine and Gray competing risks analysis, there was an improvement in PCSS with the use of statins (10-year survival $94.1 \%$ versus $91.2 \%, P=0.031$, Figure 1) and with ASA (93.4\% versus $91.3 \%, P=0.004)$. Neither statin nor ASA use was associated with OS $(P=0.83$ and 0.37 , resp.). As expected, those with higher risk prostate cancer had reduced PCSS and OS (both $P<0.001$ ), and men with higher comorbidity had inferior 10 -year OS: $67 \%, 56 \%$, and $47 \%$ for CCI score 0,1 , and $\geq 2$, respectively $(P<0.001)$. 
TABLE 1: Patient, tumor, and treatment characteristics in the entire cohort and according to use of statin and ASA.

\begin{tabular}{|c|c|c|c|c|c|}
\hline Characteristics & $\begin{array}{l}\text { Entire cohort } \\
(N=3851)\end{array}$ & $\begin{array}{c}\text { No statin/ASA } \\
(n=2428) \\
\end{array}$ & $\begin{array}{l}\text { Statin, no ASA } \\
\quad(n=506)\end{array}$ & $\begin{array}{l}\text { ASA, no statin } \\
\quad(n=509)\end{array}$ & $\begin{array}{c}\text { Statin + ASA } \\
(n=408)\end{array}$ \\
\hline Median age & $71 \mathrm{yrs}$ & $71 \mathrm{yrs}$ & $71 \mathrm{yrs}$ & $72 \mathrm{yrs}$ & $72 \mathrm{yrs}$ \\
\hline \multicolumn{6}{|l|}{$\begin{array}{l}\text { Charlson comorbidity } \\
\text { index }\end{array}$} \\
\hline 0 & $65 \%(2507)$ & $73 \%(1773)$ & $51 \%(260)$ & $62 \%(313)$ & $40 \%(161)$ \\
\hline 1 & $25 \%(961)$ & $20 \%(473)$ & $33 \%(166)$ & $29 \%(145)$ & $43 \%(177)$ \\
\hline$\geq 2$ & $10 \%(383)$ & $7.5 \%(182)$ & $16 \%(80)$ & $10 \%(51)$ & $17 \%(70)$ \\
\hline Low risk & $14 \%(563)$ & $14 \%(334)$ & $15 \%(80)$ & $14 \%(72)$ & $17 \%(69)$ \\
\hline Intermediate risk & $39 \%(1534)$ & $37 \%(900)$ & $40 \%(201)$ & $46 \%(236)$ & $45 \%(182)$ \\
\hline High risk & $44 \%(1718)$ & $47 \%(1141)$ & $33 \%(217)$ & $38 \%(191)$ & $36 \%(146)$ \\
\hline Null risk & $2 \%(83)$ & $2 \%(53)$ & $2 \%(8)$ & $2 \%(10)$ & $2 \%(11)$ \\
\hline $\begin{array}{l}\text { Radiation dose Gy } \\
{ }^{\mathrm{a}} \text { Median (range) } \\
\end{array}$ & 70 Gy (50-80 Gy) & 70 Gy (52.50-78 Gy) & 70 Gy (52.50-78 Gy) & 70 Gy (52.50-78 Gy) & 70 Gy (52.50-78 Gy) \\
\hline $\begin{array}{l}\text { Radiation dose } \\
\mathrm{BED}_{1.5} \\
{ }^{\mathrm{a}} \mathrm{Median} \text { (range) } \\
\end{array}$ & $163(126-201)$ & $163(126-201)$ & $163(133-201)$ & $163(128-195)$ & $163(140-182)$ \\
\hline Frequency $\mathrm{ADT}^{\mathrm{b}}$ use & $67 \%$ & $71 \%$ & $61 \%$ & $63 \%$ & $59 \%$ \\
\hline $\begin{array}{l}\text { Mean duration } \mathrm{ADT}^{2} \\
\text { (if used) }\end{array}$ & $16 \mathrm{mo}$ & $18 \mathrm{mo}$ & $18 \mathrm{mo}$ & $18 \mathrm{mo}$ & $1 \mathrm{mo}$ \\
\hline
\end{tabular}

${ }^{\mathrm{a}} \mathrm{RT}$ : radiation therapy; ${ }^{\mathrm{b}} \mathrm{ADT}$ : androgen deprivation therapy.

TABle 2: Prostate cancer survival.

(a) Prostate cancer specific survival (PCSS) calculated using competing risk analysis by Fine and Gray

\begin{tabular}{lccc}
\hline & Treatment & No treatment & $P$ value \\
\hline Statin & $94.1 \%$ & $91.2 \%$ & 0.031 \\
ASA & $93.4 \%$ & $91.3 \%$ & 0.004 \\
\hline
\end{tabular}

(b) Overall survival, Kaplan-Meier log rank analysis

\begin{tabular}{lccc}
\hline & Treatment & No treatment & $P$ value \\
\hline Statin & $63.1 \%$ & $62.3 \%$ & 0.827 \\
ASA & $61.8 \%$ & $62.8 \%$ & 0.371 \\
\hline
\end{tabular}

The univariate and multivariate hazard ratio model using competing risks is reported for PCSS in Table 3. As expected, lower risk cancers (lower iPSA, T-stage, and Gleason score) were associated with improved PCSS on both univariate and multivariate analysis. However, increased comorbidity, as reflected by CCI score $\geq 2$, had improved PCSS; this is likely due to the influence of competing risks. The improved PCSS seen on univariate analysis in statin and ASA users was not borne out in the multivariate model.

\section{Discussion}

This study is among the first to examine prostate cancer survival outcome relative to both statin and ASA use with comorbidity in a population-based cohort of men with localized prostate cancer treated with curative intent EBRT. When taking comorbidity into account using a multivariate completing risks analysis, neither statin nor ASA use was associated with PCSS.

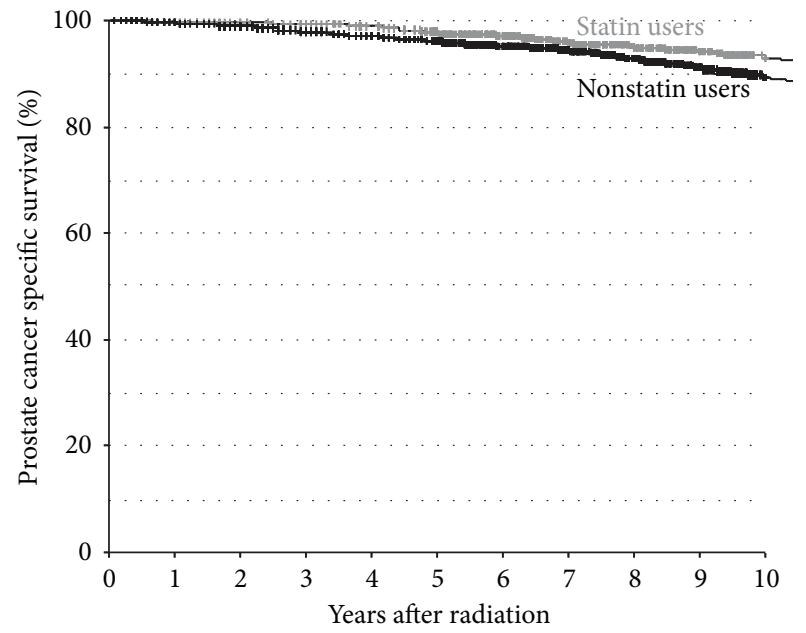

FIGURE 1: Prostate cancer specific survival between statin users and nonusers.

Population-based studies are typically undertaken to determine whether or not laboratory results are observed at a clinical level. Some studies suggest that statin use is associated with reduced risks of prostate cancer, especially with more aggressive disease [21-23], with larger benefits seen with longer duration [21, 23] and dose [23] of medication, but other studies have not been conclusive in this regard [2426]. Tagalakis et al. [27] showed that, at a population level, men who used anticoagulants were less likely to be diagnosed with prostate cancer, a decrease in risk that was not seen for any other urogenital cancer and appeared to be related to the duration of medication use. Other studies have also reported a reduced risk of prostate cancer from the use of Warfarin 


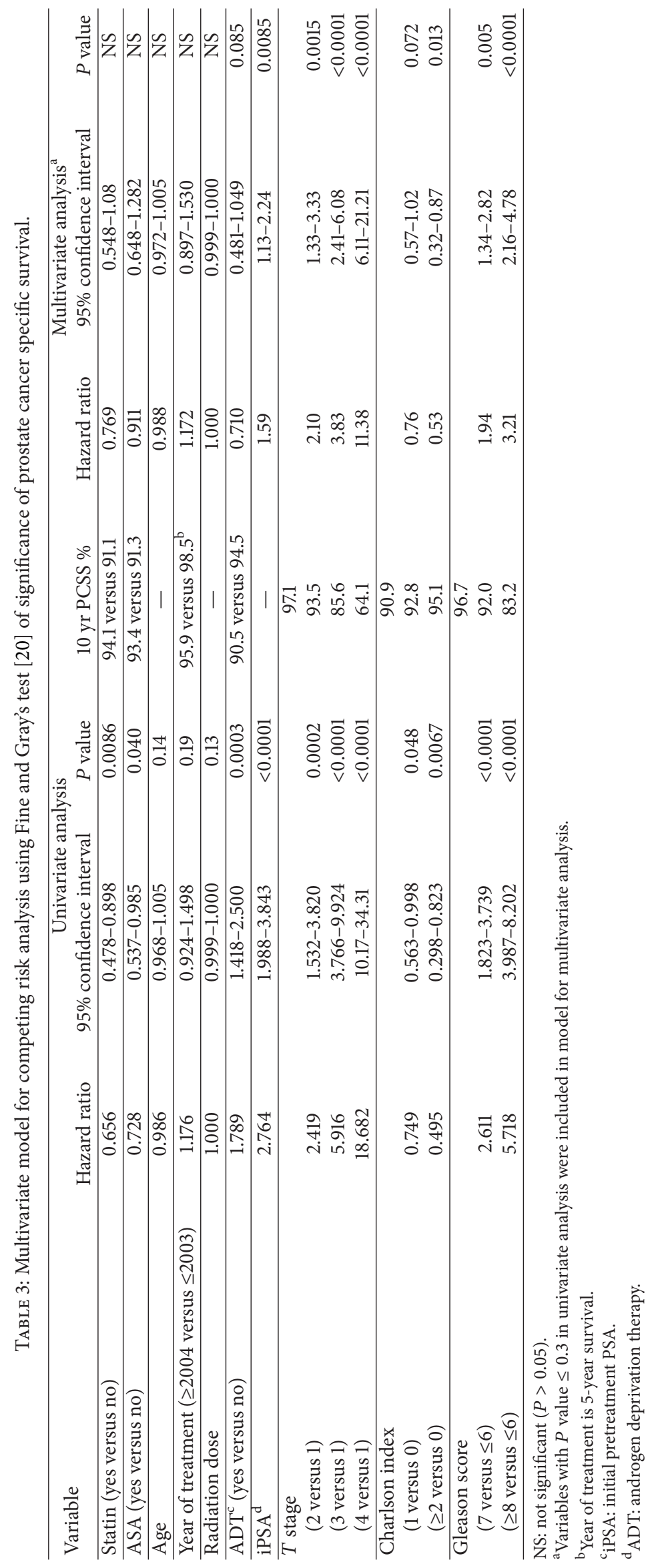


[28] and Aspirin [29] but again this has not been established unanimously [30].

If there is a potential benefit from statins or ASA in lowering the risk of prostate cancer, could the use of these medications affect outcomes in men with known prostate cancer? Several retrospective studies have examined this question with conflicting results. Some investigators [31], but not others [32-34], have reported improved biochemical control among men on statins who underwent radical prostatectomy. Others have observed better biochemical control with statin use in men treated with EBRT $[13,14]$ and have postulated that this may have been mediated through cholesterol or LDL [13]. Statin use was not associated with biochemical control among patients with prostate cancer treated with brachytherapy, perhaps because of the very high control rates achieved with this modality in comparison with EBRT [33]. Similarly studies, which included ASA with other anticoagulants, found improved biochemical control in prostate cancer patients for patients on such medication [12].

Statin use has been associated with better progressionfree survival [16] and lower recurrence risk [15] among men with prostate cancer treated with curative intent on univariate but not multivariate analysis [16]. Gutt et al. [13] found statin use to be associated with better relapse-free survival and freedom from androgen deprivation therapy but not overall or cause-specific survival. The effect ASA may have on prostate cancer outcomes is similarly controversial. In 2012 alone, studies have been published and have found both no association [11] and reduced risk [12] of cancer specific mortalityin men who receive surgery or radiotherapy for prostate neoplasia.

Available studies examining prostate cancer specific and overall survival outcomes in association with statin or ASA use have been limited by a lack of information on subjects' comorbidity. The current study, which used the Charlson comorbidity index, a standardized and validated tool to examine comorbidity, demonstrated that men with a lower CCI had a lower risk of death compared to men with a higher CCI. Statin and ASA medication was used more commonly among men with higher CCI, particularly cardiovascular conditions, warranting the prescription of these medications.

There are several limitations of this study. It is a retrospective review and therefore the reporting of data, including medication use and comorbidities, may not have been complete. Medication use was obtained from the patient's written response to a question at the time of clinic admission and was then transcribed into the consultation record and may be subject to potential inaccuracy in reporting. Medication duration (prior and subsequent to treatment) and compliance was unknown. Our sample size, although large, might not have been enough to detect small difference in PCSS in those taking statins or ASA. Endpoints such as biochemical failure or metastasis-free survival were not reliably available. Death information was obtained from automated lists from BC Vital Statistics Agency, and annual updates from the Canadian national death registry are made. There is little outmigration from $\mathrm{BC}$, but some men's vital statistics may be missing if they emigrated from BC or Canada. Despite these limitations, the current study's findings are of value in documenting the frequency of statin and ASA use among patients with localized prostate cancer and the associated survival outcomes stratified by comorbidity. These findings may be used to inform study design and sample estimates for future trials examining the use of these medications in the setting of prostate cancer [35].

\section{Conclusion}

Statin and ASA use were associated with improved PCSS on univariate analysis but not on multivariate analysis when assessed for competing risks. As expected, statin and ASA are used more often with increased comorbidity, which is significantly associated with worse survival.

Prospective evaluation of the impact of statin use in men with prostate cancer treated with radiation therapy is warranted because of the potential for reducing the mortality of prostate cancer, which remains the 3 rd commonest cause of cancer death in the Western world.

\section{Conflict of Interests}

The authors declare that there is no conflict of interests regarding the publication of this paper.

\section{Acknowledgment}

This research was presented in poster form at CARO Conference in Winnipeg, MB, Canada, September 2011 and ASTRO Conference in Miami, FL, USA, October 2011.

\section{References}

[1] e-CPS English, "e-CPS : Drug Monographs : HMG-CoA Reductase Inhibitors (CPhA Monograph)," 2011, https://www.e-therapeutics.ca/cps.showMonograph.action?simpleMonographId= $\mathrm{m} 250500$.

[2] R. J. Hamilton, K. C. Goldberg, E. A. Platz, and S. J. Freedland, "The influence of statin medications on prostate-specific antigen levels," Journal of the National Cancer Institute, vol. 100, no. 21, pp. 1511-1518, 2008.

[3] H. Y. Oh, E. J. Lee, S. Yoon, B. H. Chung, K. S. Cho, and S. J. Hong, "Cholesterol level of lipid raft microdomains regulates apoptotic cell death in prostate cancer cells through EGFRmediated Akt and ERK signal transduction," The Prostate, vol. 67, no. 10, pp. 1061-1069, 2007.

[4] L. Yang, M. Egger, R. Plattner, H. Klocker, and I. E. Eder, "Lovastatin causes diminished PSA secretion by inhibiting AR expression and function in LNCaP prostate cancer cells," Urology, vol. 77, no. 6, pp. 1508.el-1508.e7, 2011.

[5] A. Yokomizo, M. Shiota, E. Kashiwagi et al., "Statins reduce the androgen sensitivity and cell proliferation by decreasing the androgen receptor protein in prostate cancer cells," The Prostate, vol. 71, no. 3, pp. 298-304, 2011.

[6] D. J. Mener, "Prostate specific antigen reduction following statin therapy: mechanism of action and review of the literature," IUBMB Life, vol. 62, no. 8, pp. 584-590, 2010.

[7] e-CPS English, "e-CPS : Drug Monographs : Aspirin," 2011, https://www.e-therapeutics.ca/cps.showMonograph.action? simpleMonographId $=\mathrm{m} 069600$. 
[8] R. E. Harris, J. Beebe-Donk, H. Doss, and D. Burr Doss, "Aspirin, ibuprofen, and other non-steroidal anti-inflammatory drugs in cancer prevention: a critical review of non-selective COX-2 blockade (review)," Oncology Reports, vol. 13, no. 4, pp. 559-583, 2005.

[9] A. Falanga, M. Marchetti, A. Vignoli, and D. Balducci, "Clotting mechanisms and cancer: implications in thrombus formation and tumor progression," Clinical Advances in Hematology \& Oncology, vol. 1, no. 11, pp. 673-678, 2003.

[10] T. Veitonmaki, T. L. Tammela, A. Auvinen, and T. J. Murtola, "Use of aspirin, but not other non-steroidal anti-inflammatory drugs is associated with decreased prostate cancer risk at the population level," European Journal of Cancer, vol. 49, no. 4, pp. 938-945, 2013.

[11] P. K. Dhillon, S. A. Kenfield, M. J. Stampfer, E. L. Giovannucci, and J. M. Chan, "Aspirin use after a prostate cancer diagnosis and cancer survival in a prospective cohort," Cancer Prevention Research, vol. 5, no. 10, pp. 1223-1228, 2012.

[12] K. S. Choe, D. Correa, A. B. Jani, and S. L. Liauw, "The use of anticoagulants improves biochemical control of localized prostate cancer treated with radiotherapy," Cancer, vol. 116, no. 7, pp. 1820-1826, 2010.

[13] R. Gutt, N. Tonlaar, R. Kunnavakkam, T. Karrison, R. R. Weichselbaum, and S. L. Liauw, "Statin use and risk of prostate cancer recurrence in men treated with radiation therapy," Journal of Clinical Oncology, vol. 28, no. 16, pp. 2653-2659, 2010.

[14] M. A. Kollmeier, M. S. Katz, K. Mak et al., "Improved biochemical outcomes with statin use in patients with high-risk localized prostate cancer treated with radiotherapy," International Journal of Radiation Oncology, Biology, Physics, vol. 79, no. 3, pp. 713718, 2011.

[15] E. R. Mora, J. A. L. Garin, O. B. Gali, A. F. Comalat, L. F. Ciutat, and O. A. Toro, "The impact of statins use in clinically localized prostate cancer treated with radical prostatectomy," Actas Urologicas Espanolas, vol. 33, no. 4, pp. 351-355, 2009.

[16] D. E. Soto, S. Daignault, H. M. Sandler, and M. E. Ray, "No effect of statins on biochemical outcomes after radiotherapy for localized prostate cancer," Urology, vol. 73, no. 1, pp. 158-162, 2009.

[17] A. V. D'Amico, "Statin use and the risk of prostate-specific antigen recurrence after radiation therapy with or without hormone therapy for prostate cancer," Journal of Clinical Oncology, vol. 28, no. 16, pp. 2651-2652, 2010.

[18] M. Extermann, "Measuring comorbidity in older cancer patients," European Journal of Cancer, vol. 36, no. 4, pp. 453-471, 2000.

[19] M. E. Charlson, P. Pompei, K. A. Ales, and C. R. MacKenzie, "A new method of classifying prognostic comorbidity in longitudinal studies: development and validation," Journal of Chronic Diseases, vol. 40, no. 5, pp. 373-383, 1987.

[20] J. P. Fine and R. J. Gray, "A proportional hazards model for the subdistribution of a competing risk," Journal of the American Statistical Association, vol. 94, no. 446, pp. 496-509, 1999.

[21] R. H. Breau, R. J. Karnes, D. J. Jacobson et al., "The association between statin use and the diagnosis of prostate cancer in a population based cohort," The Journal of Urology, vol. 184, no. 2, pp. 494-499, 2010.

[22] E. A. Platz, M. F. Leitzmann, K. Visvanathan et al., "Statin drugs and risk of advanced prostate cancer," Journal of the National Cancer Institute, vol. 98, no. 24, pp. 1819-1825, 2006.

[23] J. Shannon, S. Tewoderos, M. Garzotto et al., "Statins and prostate cancer risk: a case-control study," American Journal of Epidemiology, vol. 162, no. 4, pp. 318-325, 2005.
[24] L. Blais, A. Desgagné, and J. LeLorier, "3-hydroxy-3-methylglutaryl coenzyme a reductase inhibitors and the risk of cancer: a nested case-control study," Archives of Internal Medicine, vol. 160, no. 15, pp. 2363-2368, 2000.

[25] S. Friis, A. H. Poulsen, S. P. Johnsen et al., "Cancer risk among statin users: a population-based cohort study," International Journal of Cancer, vol. 114, no. 4, pp. 643-647, 2005.

[26] M. R. Graaf, A. B. Beiderbeck, A. C. G. Egberts, D. J. Richel, and H.-J. Guchelaar, "The risk of cancer in users of statins," Journal of Clinical Oncology, vol. 22, no. 12, pp. 2388-2394, 2004.

[27] V. Tagalakis, H. Tamim, M. Blostein, J.-P. Collet, J. A. Hanley, and S. R. Kahn, "Use of warfarin and risk of urogenital cancer: a population-based, nested case-control study," The Lancet Oncology, vol. 8, no. 5, pp. 395-402, 2007.

[28] S. Schulman and P. Lindmarker, "Incidence of cancer after prophylaxis with warfarin against recurrent venous thromboembolism," The New England Journal of Medicine, vol. 342, no. 26, pp. 1953-1958, 2000.

[29] E. J. Jacobs, M. J. Thun, E. B. Bain, C. Rodriguez, S. J. Henley, and E. E. Calle, "A large cohort study of long-term daily use of adultstrength aspirin and cancer incidence," Journal of the National Cancer Institute, vol. 99, no. 8, pp. 608-615, 2007.

[30] L. R. Zacharski, W. G. Henderson, F. R. Rickles et al., "Effect of warfarin anticoagulation on survival in carcinoma of the lung, colon, head and neck, and prostate. Final report of VA Cooperative Study \#75," Cancer, vol. 53, no. 10, pp. 2046-2052, 1984.

[31] R. J. Hamilton, L. L. Banez, W. J. Aronson et al., "Statin medication use and the risk of biochemical recurrence after radical prostatectomy: results from the Shared Equal Access Regional Cancer Hospital (SEARCH) Database," Cancer, vol. 116, no. 14, pp. 3389-3398, 2010.

[32] L. S. Krane, S. A. Kaul, H. J. Stricker, J. O. Peabody, M. Menon, and P. K. Agarwal, "Men presenting for radical prostatectomy on preoperative statin therapy have reduced serum prostate specific antigen," The Journal of Urology, vol. 183, no. 1, pp. 118124, 2010.

[33] M. A. Moyad, G. S. Merrick, W. M. Butler et al., "Statins, especially atorvastatin, may favorably influence clinical presentation and biochemical progression-free survival after brachytherapy for clinically localized prostate cancer," Urology, vol. 66, no. 6, pp. 1150-1154, 2005.

[34] J. H. Ku, C. W. Jeong, Y. H. Park, M. C. Cho, C. Kwak, and H. H. Kim, "Relationship of statins to clinical presentation and biochemical outcomes after radical prostatectomy in Korean patients," Prostate Cancer and Prostatic Diseases, vol. 14, no. 1, pp. 63-68, 2011.

[35] T. J. Murtola, "Statin use is associated with improved prostate cancer survival: is it time for a clinical trial?" Expert Review of Anticancer Therapy, vol. 10, no. 10, pp. 1563-1567, 2010. 


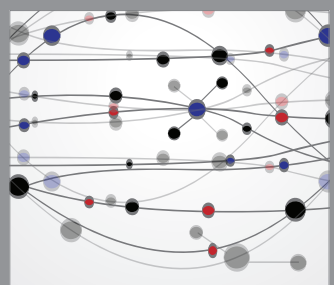

The Scientific World Journal
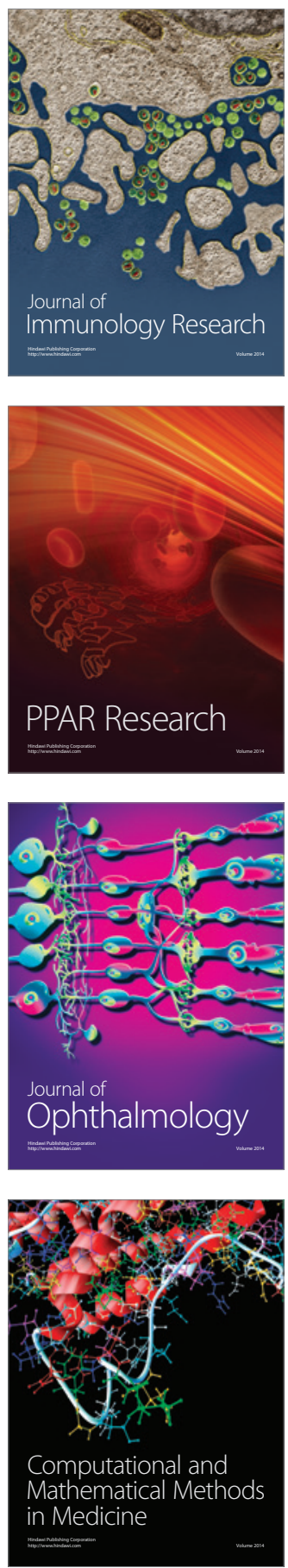

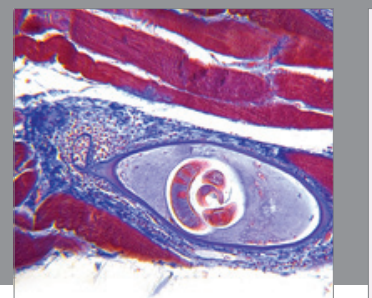

Gastroenterology

Research and Practice
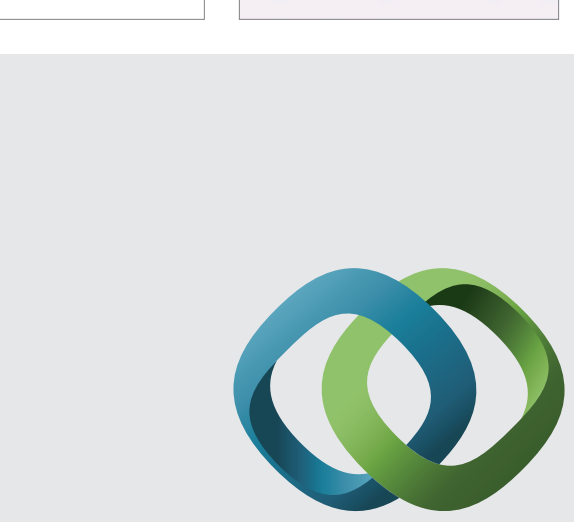

\section{Hindawi}

Submit your manuscripts at

http://www.hindawi.com
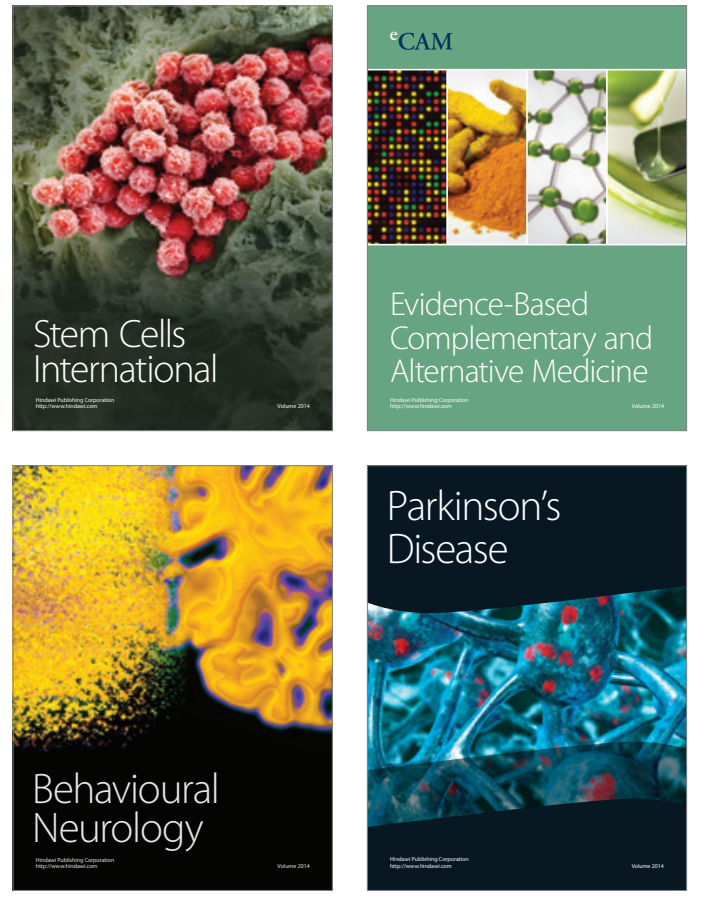
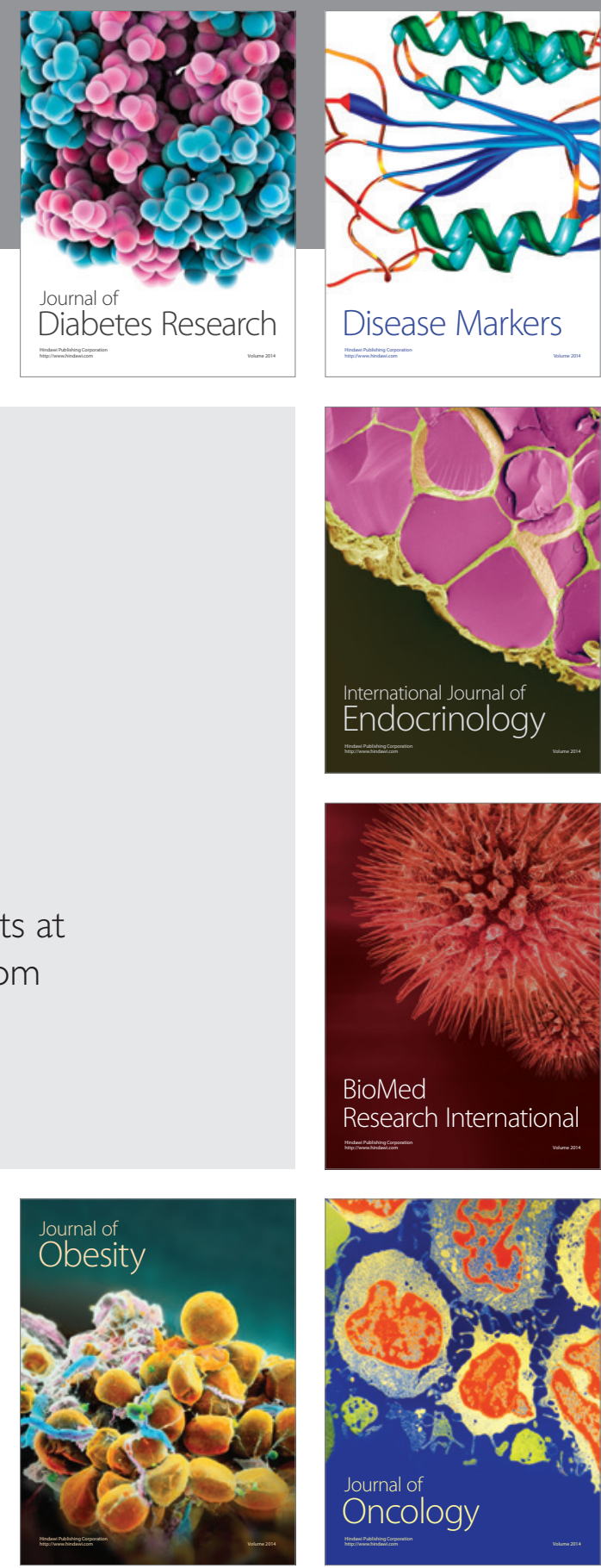

Disease Markers
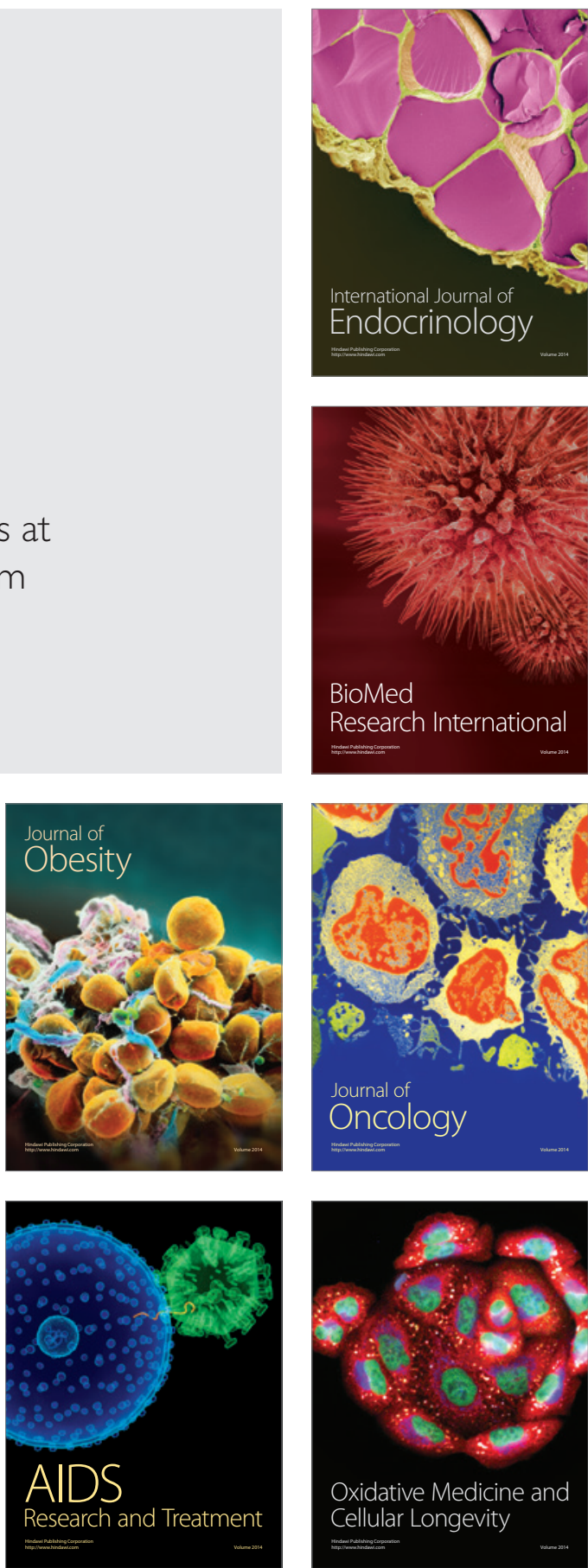